\title{
Hetero-modulus Nanoparticles Reinforced Corundum Matrix CMC with Extreme Wear and Thermal Shock Resistances
}

\author{
László A. Gömze ${ }^{1, a}$ Ludmila N. Gömze ${ }^{2, b}$ \\ ${ }^{1}$ Department of Ceramics and Silicate Engineering, University of Miskolc, Hungary \\ ${ }^{2}$ IGREX Engineering Service Ltd., Igrici, Hungary \\ afemgomze@uni-miskolc.hu; igrex2009@yandex.ru
}

Keywords: hetero-modulus, ceramics, alumina, CMC, c- $\mathrm{Si}_{3} \mathrm{~N}_{4}$, diamond, nanoparticles, wear, thermal shock

\begin{abstract}
:
A novel approach to obtain ceramic matrix composites with extreme high mechanical wear and thermal shock resistance abilities is presented. The developed corundum matrix composites were reinforced with nanoparticles, submicron fibres and whiskers of $\mathrm{Si}_{2} \mathrm{ON}_{2}, \mathrm{SiAlON}, \mathrm{AlN}$ and $\mathrm{Si}_{3} \mathrm{~N}_{4}$. These kinds of materials have several Young's modulus simultaneously. These new alumina based ceramic matrix composites were obliged to collisions with different metallic bodies having high densities and impact speeds larger than $900 \mathrm{~m} / \mathrm{s}$ at the moment of the hits. During the experiments in the places of collisions where oxygen was absent new high density ,diamond-like” c-Si $\mathrm{N}_{4}$ cubic crystals have developed with spinel structures, where nitrogen atoms were distributed in the centres of the cubes. These new spinel crystals of $\mathrm{c}-\mathrm{Si}_{3} \mathrm{~N}_{4}$ in the alumina matrix have extreme high dynamic strength, hardness and wear resistance, like diamond. They were fully resistance to oxygen and thermal shock at the tested temperature of $1200{ }^{\circ} \mathrm{C}$.
\end{abstract}

\section{Introduction}

Several kinds of ceramic materials and ceramic matrix composites with submicron and nanoparticles were developed for different industrial and biomedical purposes [1-9] in the last 1015 years. There were also developed ceramic materials CMC-s with extreme high values of mechanical strength, hardness and wear resistance [10-16]. Some of them are made from heteromodulus ceramics $[12,14]$ and have very good resistance to high temperature and thermal shock. The hetero-modulus ceramic materials and CMC-s give us an opportunity to combine ceramic matrix having high Young's modulus $(200-400 \mathrm{GPa})$ with additions of particulate or fibrous phases having significantly higher $(500-800 \mathrm{GPa})$ or lower $(10-60 \mathrm{GPa})$ Young's modulus. The thermal shock resistance of brittle ceramic compounds, such as hard oxides, carbides, nitrides, borides can be developed to a considerable extent by addition of lower modulus particles. These ceramics and CMC-s because of their hetero-modulus material structures have inherent ability to absorb and dissipate the elastic energy and divert the crack propagation. Opposite to hetero-modulus materials the traditional hard metals, oxide, carbide, nitride, boride and silicone ceramics and CMC-s usually have material structures with relatively big crystals with high rigidness and have strong inclination to nick, pitting and rigid fractures $[17,18]$.

The physical and mechanical properties including the mechanical strength, hardness, wear and thermal shock resistances of technical ceramics and CMC-s are very strong dependent both on chemical compositions, crystal structures and the used technological conditions and processes [9, $10,19,20,21]$. These technological parameters are the followings:

- The grain sizes and shapes of the used raw material powders and their distribution in the forming instruments before, during and after compacting.

- The volumes, sorts and distributions of mechanical pressures in the ceramic powders during their compacting. 
- The level of relaxation of the mechanical residual stresses inside the compacted ceramic items after forming and before sintering.

- The level and time of relaxation of thermo-mechanical stresses developed in ceramic and $\mathrm{CMC}$ items during sintering at high temperatures.

The level of recrystallization and residual thermo-mechanical stresses strong depend on firing conditions including firing curves, temperatures and atmospheres [19, 22, 23, 24, 25].

The aims of present contribution are:

- Develop hetero-modulus corundum matrix composite materials with extreme mechanical properties including dynamic strength, wear and thermal shock resistance.

- Show the opportunities of ,cold" phase transformation of pre-compacted and pre-sintered $\alpha$ $\mathrm{Si}_{3} \mathrm{~N}_{4}$ and $\beta-\mathrm{Si}_{3} \mathrm{~N}_{4}$ into cubic c- $\mathrm{Si}_{3} \mathrm{~N}_{4}$ silicon nitride diamonds of spinel crystalline structures.

\section{Materials and experimental procedures}

To produce hetero-modulus corundum matrix composite (CMC) materials and specimens for further examination on material structure, phase transformation and recrystallization well known and relatively not expensive alumina powders of different purity were used. These powders were polluted with quartz, thallium-oxide and metallic aluminium to a small extent. The content of $\mathrm{Al}_{2} \mathrm{O}_{3}$ was higher than $92 \%$ in each case of experiments. The specimens were manufactured by uniaxial pressing method applying pressures from $400 \mathrm{MPa}$ to $600 \mathrm{MPa}$. The shapes of specimens were cylindrical and quadrangular prism and they were pre-sintered in nitrogen $\left(\mathrm{N}_{2}\right)$ atmosphere under special firing curves. Due to phase transformation and recrystallization occurred during presintering, a new hetero-modulus corundum matrix CMC was developed (Fig. 1.), reinforced with submicron and nanoparticles of $\mathrm{Si}_{2} \mathrm{ON}_{2}, \mathrm{AlN}$ and $\alpha-\mathrm{Si}_{3} \mathrm{~N}_{4}$

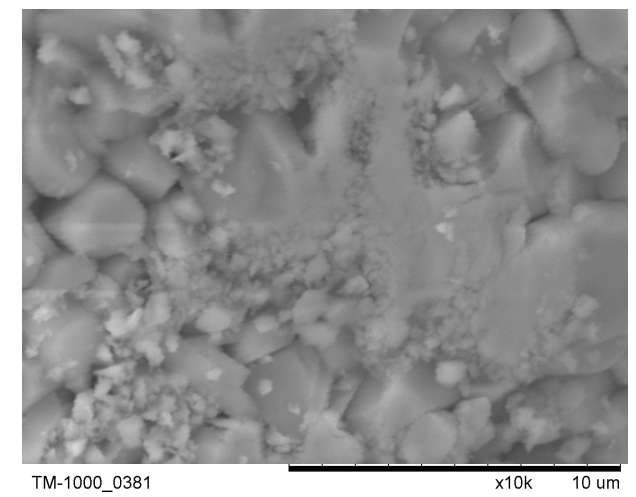

Fig. 1. The material structures of developed hetero-modulus corundum matrix $\mathrm{CMC}$ with $\alpha-\mathrm{Si}_{3} \mathrm{~N}_{4}$ particles

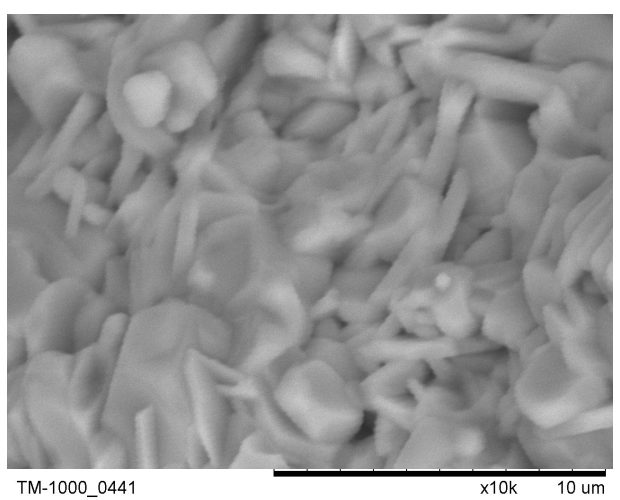

Fig. 2. The material structures of developed hetero-modulus corundum matrix CMC with $\beta-\mathrm{Si}_{3} \mathrm{~N}_{4}$ particles

There are several methods to develop SiAlON particles and transform $\alpha-\mathrm{Si}_{3} \mathrm{~N}_{4}$ into $\beta$-Si $\mathrm{Si}_{4}$, but all of them have used sintering temperatures much above $1700{ }^{\circ} \mathrm{C}$ or hot-pressing at $1850{ }^{\circ} \mathrm{C}$ under pressure of $23 \mathrm{MPa}$ or more [26-30]. In present work a reactive pre-sintering was used in nitrogen $\left(\mathrm{N}_{2}\right)$ atmosphere at temperature from $1350{ }^{\circ} \mathrm{C}$ to $1550{ }^{\circ} \mathrm{C}$. In results of pre-sintering SiAlON and stabilized AIN particles were developed in the corundum matrix and the crystals of $\alpha-\mathrm{Si}_{3} \mathrm{~N}_{4}$ have transformed into $\beta-\mathrm{Si}_{3} \mathrm{~N}_{4}$ which growth in longitudinal direction prismatic hexagonal rod-like crystals (Fig. 2). These crystals impinge on each other forming an interlock microstructure [31].

To achieve extreme mechanical and thermal properties, hardness, wear and thermal shock resistance of hetero-modulus corundum matrix composites reinforced with $\mathrm{Si}_{2} \mathrm{ON}_{2}, \mathrm{SiAlON}, \mathrm{AlN}_{2}$, $\alpha-\mathrm{Si}_{3} \mathrm{~N}_{4}$ and $\beta-\mathrm{Si}_{3} \mathrm{~N}_{4}$ a special, high energy dynamic compacting method with high speed flying punches (Fig. 3) was developed and used. 


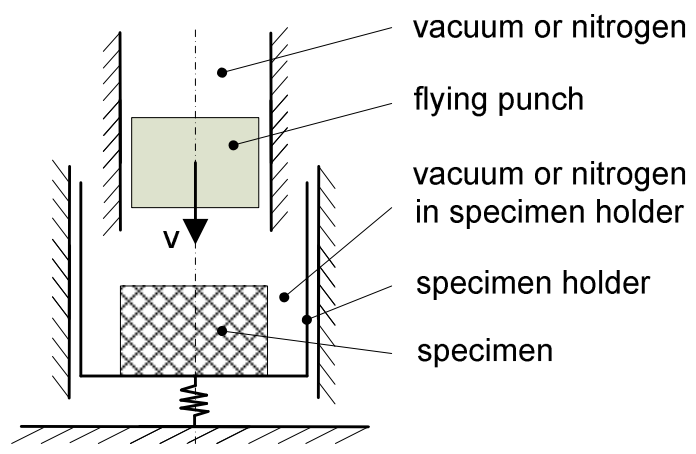

Fig. 3. Principles of dynamic compacting method with high speed flying punches

The flying punches are made from hard metal alloys or from RBSN and HPSN silicon nitride ceramics and flying in vacuum or in nitrogen $\left(\mathrm{N}_{2}\right)$ atmosphere of pressure less than $0,1 \mathrm{MPa}$ and have speeds more than $900 \mathrm{~m} / \mathrm{s}$.

To examine the thermal shock behaviour of developed hetero-modulus corundum matrix ceramic composites reinforced with different nitrides, including cubic c- $\mathrm{Si}_{3} \mathrm{~N}_{4}$ diamond particles, quenching tests under water were used.

\section{Results and discussion}

Improvement of mechanical and thermal properties including dynamic strength [15, 32], hardness [33, 34], wear [12, 35] and thermal shock [14, 36, 37, 38] resistance is very important in development of high performance ceramics and CMC-s. Because of this, several methods were developed to achieve phase transformation in silicon nitride ceramics and obtain $\mathrm{Si}_{3} \mathrm{~N}_{4}$ particles with extreme mechanical properties and dynamic strength [24, 31, 32, 38, 39, 40, 41], but no one of them used flying punches with speeds higher than $900 \mathrm{~m} / \mathrm{s}$ to generate phase transformation process at „room-temperature”. During the hits of flying punches into hetero-modulus corundum matrix composite specimens reinforced with $\mathrm{Si}_{2} \mathrm{ON}_{2}, \mathrm{AlN}, \alpha-\mathrm{Si}_{3} \mathrm{~N}_{4}, \mathrm{SiAlON}$, and $\beta-\mathrm{Si}_{3} \mathrm{~N}_{4}$, the kinetic energy of flying punches is engorged (Eq.1) by fractures, heating and phase transformation with recrystallization of material particles in the place and surrounding of the collisions:

$$
W_{k}=W_{F}+W_{H}+W_{P T}, \quad[\mathrm{Nm}]
$$

where:

$\mathrm{W}_{\mathrm{k}}$ - kinetic energy of flying punches $[\mathrm{Nm}]$,

$\mathrm{W}_{\mathrm{F}}$ - energy engorgement through fractures $[\mathrm{Nm}]$,

$\mathrm{W}_{\mathrm{H}}$ - energy engorgement through local heating [Nm],

$\mathrm{W}_{\mathrm{PT}}$ - part of kinetic energy turned to phase transformation and recrystallization of material

particles both of flying punches and corundum matrix composite specimens in the

place and surrounding of the hits and collisions.

When flying punches have homogeneous density and the specimens are made from heteromodulus materials like corundum matrix composite reinforced with $\mathrm{Si}_{2} \mathrm{ON}_{2}, \mathrm{AlN}, \alpha-\mathrm{Si}_{3} \mathrm{~N}_{4} \mathrm{SiAlON}$, and $\beta-\mathrm{Si}_{3} \mathrm{~N}_{4}$ particles with several Young's modulus, the part of kinetic energy turned on heating and phase transformation were mathematically determined and described in [18] and [23].

When flying punches have high densities and speeds higher than $900 \mathrm{~m} / \mathrm{s}$, a huge volume of kinetic energy is turning to phase transformation, which is accompanied with local temperature over $1000{ }^{\circ} \mathrm{C}$ and mechanical stress larger than $(150$ - 200) GPa. Due to high pressures and local overheating, phase transformation and recrystallization could be observed both in alumina polycrystals and $\alpha-\mathrm{Si}_{3} \mathrm{~N}_{4}$ and $\beta-\mathrm{Si}_{3} \mathrm{~N}_{4}$ nanoparticles of hetero-modulus corundum matrix composites reinforced with different nitrides. The geometrical sizes of alumina poly-crystals had grown considerable (Fig. 4.) and the density of corundum matrix also had increased. At the same time the 
particles of $\alpha-\mathrm{Si}_{3} \mathrm{~N}_{4}$ and $\beta-\mathrm{Si}_{3} \mathrm{~N}_{4}$ transformed into diamond-like cubic c- $\mathrm{Si}_{3} \mathrm{~N}_{4}$ of spinel crystalline structure (Fig. 5.).

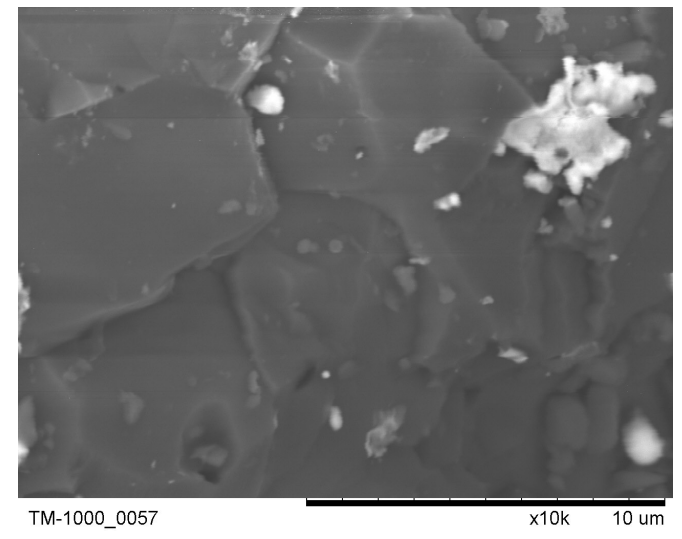

Fig. 4. The material structures of recrystallised alumina poly-crystals

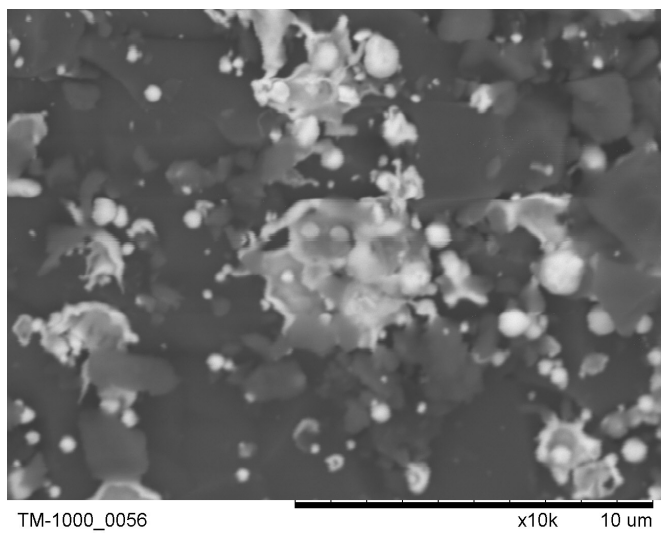

Fig. 5. The material structures of recrystallised c- $\mathrm{Si}_{3} \mathrm{~N}_{4}$ silicon nitride diamonds

Using the new developed high kinetic energy compacting method, both the corundum matrix crystals (Fig.4.) and the formed $\mathrm{c}-\mathrm{Si}_{3} \mathrm{~N}_{4}$ spinel silicon nitride diamond crystals (Fig.5.) are polluted with melted particles of high speed metallic flying punches. Disadvantages of metallic and metal alloy flying punches are their damages and mackles on the surfaces of re-compacted specimens (Fig.6.) and their aptitude and inclination to oxidation (Fig. 7.) The metallic particles of high speed flying punches behave as a reducer material and they can take oxygen ions from the contact surface of corundum matrix, decreasing its physical, chemical and mechanical properties. Because of this, the best materials for high speed flying punches with high kinetic energy are HPSN-s, the dense sintered silicon nitrides.

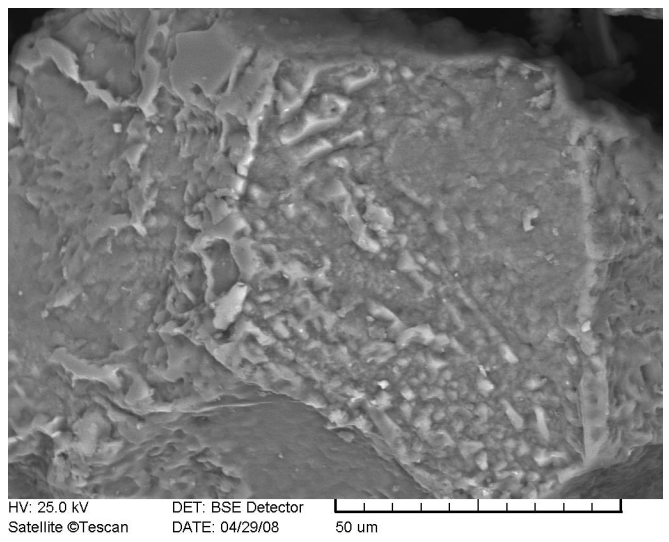

Fig. 6. Mackles of metallic flying punches material on surface of recrystallised CMC specimens

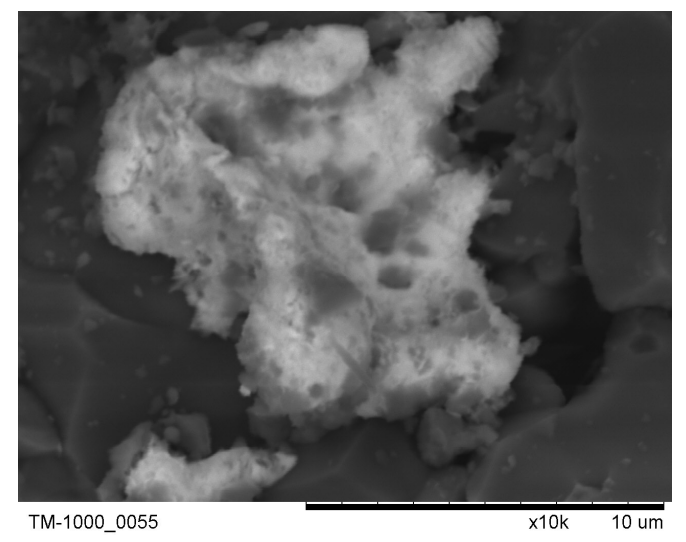

Fig. 7. Mackles and oxidation of metallic flying punches particles on surface of CMC specimens

To examine the thermal shock resistance of developed hetero-modulus corundum matrix composites, reinforced with different silicon nitrides including cubic c- $\mathrm{Si}_{3} \mathrm{~N}_{4}$ diamond particles, quenching tests under water were used. For thermal shock tests the specimens had geometrical forms of disks of diameter $25 \mathrm{~mm}$ and thickness $10 \mathrm{~mm}$ and were prepared from the following 3 material compositions:

a, $\mathrm{Al}_{2} \mathrm{O}_{3}=91 \%, \mathrm{CrO}_{3}=1 \%, \mathrm{ZrO}_{2}=1 \%, \mathrm{CaO}=1 \%, \mathrm{MgO}=2 \%$ and $\mathrm{SiO}_{2}=4 \%$

b, $\mathrm{Al}_{2} \mathrm{O}_{3}=97 \%, \mathrm{MgO}=1 \%, \mathrm{CrO}_{3}=1 \%, \mathrm{SiO}_{2}=15$

c, The developed by us hetero-modulus corundum matrix composite reinforced with silicon nitrides, including c- $\mathrm{Si}_{3} \mathrm{~N}_{4}$ diamond particles.

From each material composition 100 pieces of specimens were made for examination of thermal shock properties. During the tests the specimens were heated up to $1200{ }^{\circ} \mathrm{C}$, than dropped into water 
of $20{ }^{\circ} \mathrm{C}$ temperature. The results of samples damages during thermal shock tests are shown on histograms (Fig. 8.). It can be seen from Fig.8. that $40 \%$ of specimens from material composition "a" and " $b$ " were cracked or broken but none of 100 pieces of the hetero-modulus ceramic matrix composites reinforced with silicon nitrides, including $\mathrm{c}-\mathrm{Si}_{3} \mathrm{~N}_{4}$ diamond particles were damaged after 17 cycles of water quenching test.

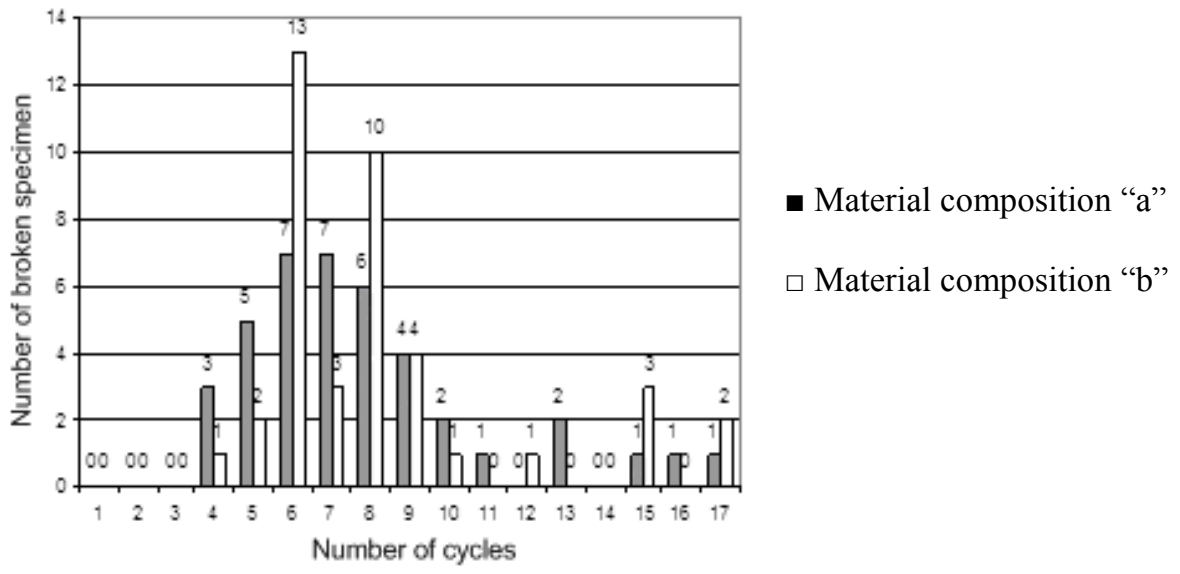

Fig. 8. The results of thermal shock quenching tests under water of $20{ }^{\circ} \mathrm{C}$

The reason is that opposite to traditional powder ceramics and hard metal alloys, there are no remarkable residual mechanical stresses in the hetero-modulus ceramics and CMC-s after forming and sintering, because of their inherent ability to absorb and dissipate the elastic energy developed by mechanical and thermo-mechanical stresses.

\section{Conclusions}

Understanding the phenomena in the collisions under high speeds and advantageous of heteromodulus materials having several Young's modulus simultaneously, new composite material was developed, reinforced with submicron and nanoparticles of $\mathrm{AlN}, \mathrm{Si}_{2} \mathrm{ON}_{2}, \mathrm{SiAlON}$ and other silicon nitrides. Using the advantageous of high energy dynamic compacting methods with high speed flying punches, at the places and surroundings of hits and collisions new, cubic c- $\mathrm{Si}_{3} \mathrm{~N}_{4}$ silicon nitride diamond particles were developed with spinel crystalline structures.

Transformation of $\alpha-\mathrm{Si}_{3} \mathrm{~N}_{4}$ and $\beta-\mathrm{Si}_{3} \mathrm{~N}_{4}$ particles into cubic c- $\mathrm{Si}_{3} \mathrm{~N}_{4}$ silicon nitride diamond spinel crystals under high energy collisions with high speed flying punches together with submicron and nanoparticles of AIN and SiAlON give to the new developed hetero-modulus corundum matrix composites not only excellent mechanical strength and surface hardness, but outstanding thermal stability, wear and thermal shock resistance at temperature drops higher than $1000{ }^{\circ} \mathrm{C}$.

\section{Acknowledgements}

The authors would like to thank to Igrex Ltd for financial support of this research in several years.

\section{References}

[1] B. Venkataraman, G. Sundararajan: Acta Materialica Vol. 44 (1996), p. 451

[2] A. Hultman, A. K. Veimark: Evolution Vol. 4. (1998), p. 25.

[3] H. Donza, R. Torrecillasa, A. H. De Azab, P. Penab and S. De Azab: Cement and Concrete Research Vol. 32 (2002), p. 1755

[4] V. Zyryanov: Interceram Vol 52 (2003), p. 22.

[5] J. Csanyi, L. A. Gomze, Zs. Kover: Epitoanyag Vol. 56 (2004), p. 103.

[6] I. L. Shabalin, V. M. Vishnyakov and .L. I. Shabalin, J. Eur. Ceram. Soc. Vol. 27 (2007), p. 2171

[7] A. Morikawa, T. Suzuki, K. Kikuta, A. Suda and H. Sinjo: Epitoanyag Vol 61 (2009), p. 2. 
[8] J. G. Chigvinadze, J. V. Acrivos, S. M. Ashimov, D. D. Gulamova, T. V. Machaidze and D. Uskenbaev: Epitoanyag Vol 61. (2009) p. 104.

[9] V. V. Lashneva, A. V. Shevchenko and E. V. Dubnik: Steklo i Keramika Vol. 4. (2009) p. 25.

[10] J. Csanyi, L. A. Gomze: Epitoanyag Vol 53. (2001), p. 66.

[11] K. Katahira, Y. Watanabe, H. Ohmori and T. Kato: Int. Journal of Machine Tools \& Manufacture Vol. 42 (2002), p. 1307.

[12] S.N. Kulkov, N. I. Savchenko: Epitoanyag Vol. 60 (2008), p. 62.

[13] A. G. Tkachev, O. N. Tkaceva; Steklo i Keramika Vol 2. (2009), p. 15.

[14] I. L. Shabalin, V. M., Vishnyakov, D. J. Bull, S. G. Keens, L. F. Yamshchikov and L. I. Shabalin: J. Alloys and Compounds Vol. 472 (2009), p. 373.

[15] N. I. Ershova, I. Yu. Kelina: Epitoanyag Vol. 61 (2009), p. 34.

[16] K. Katahira, H. Ohmori: Epitoanyag Vol. 61 (2009) p. 104.

[17] C. B. Carter, M. G. Norton: Ceramic Materials, Science and Engineering, Springer Science + Business Media, LLC., New York (2007)

[18] L. A. Gomze, L. N. Gomze, in: Proceedings of Int. Conf. XI Khariton's Readings, Extreme States of Substance; edited by DSC A. L. Mihailov, Published by FGUP „RFYaTsVNIIEF", Sarov, Russia (2009), p. 324.

[19] J. Csanyi, L. A. Gomze: Epitoanyag, Vol. 60 (2008), p. 15.

[20] V. S. Bukanov, E. S. Lukin: Steklo i Keramika Vol. 8 (2008), p. 66.

[21] J. Csanyi: Epitoanyag Vol. 61 (2009), p. 6.

[22] A. Zer, r. Riedel, T. Sekine, J. E. Lowther, W. Y. Ching and I. Tanaka: Advanced Materials (FRG) Vol. 18 (2006), p. 2933.

[23] L. A. Gomze, L. N. Gomze: Epitoanyag, Vol 61 (2009), p. 38.

[24] M. Müller, W. Bauer and R. Knitter: Ceramics International, Vol. 35 (2009), p. 38.

[25] S. H. Lee, M. Weinmann: Acta Materialica, Vol. 57 (2009), p. 4374.

[26] S. Hampshire, H. K. Park, D. P. Thompson and K. H. Jack: Nature Vol. 274 (1978), p. 880.

[27] G. G. Deeley, J. M. Herbert and N. C. Moore: Powder Metallurgy Vol. 8. (1961), p. 145.

[28] F. L. Riley: J. Am. Ceram. Soc. Vol. 83 (2000), p. 245.

[29] A. Tsuge, K. Nishida: Am. Ceram, Soc. Bull Vol. 57 (1978), p. 424.

[30] F. F. Laange: J. Ceram. Soc. Japan Vol. 114 (2006), p. 873.

[31] S. Hampshire: Materials Sci. Forum Vol. 606 (2009), p. 27.

[32] V. V. Milyavskiy, A. V. Utkin, A. Z. Zhuk, V. V. Yakushev and V. E. Fortov: Diamond and Related Materials Vol. 14 (2005), p. 1920.

[33] W. Wang, N. M. Hadfield and A. A. Wereszczak: Ceramic International Vol. 35 (2009), p. 3339.

[34] X. Li, X. Jin, L. Zhang and T. Pan: Materials Science and Engineering A, Vol. 527 (2009), p. 103.

[35] A. S. Yunoshev: Combustion, Explosion and Shock Waves, Vol. 40 (2004), p. 370.

[36] J. K. Chen, K.L. Tang and J. T. Chang: Ceramics International, Vol. 35 (2009), p. 2999.

[37] X. Zhang, Z. Wang, C. Hong, P. Hu and W. Han: Materials and Design, Vol. 30, Issue 10 (2009), p. 4552.

[38] J. G. Miranda-Hernández, S. D. de la Torre and E. Rocha-Rangel: Epitoanyag, Vol. 62., (2010), p. 2.

[39] H. He, T. Sekine, T. Kobayashi, H. Hirosaki and I. Suzuki: Physical Review B, Vol. 62, N. 17 (2000), p. 11413.

[40] T. Sekine, T. Mitsuhashi: Appl. Phys Letters, Vol. 79 (2001), p. 2719.

[41] V. V. Yakushev, A. V. Utkin and A. N. Zhukov in: Proceedings of Int. Conf. XI Khariton's Readings, Extreme States of Substance; Edited by DSc A. L. Mihailov, Published by FGUP „RFYaTs-VNIIEF”, Sarov, Russia (2009), p. 204. 